\title{
A Study of Toxic Effects of Formalin on Health of First Year Medical and Dental Students
}

\section{ABSTRACT}

Introduction: Formalin is widely and commonly used as a fixative for microscopy, histology, preservative and disinfectant, etc. Despite formalin being extensively used in different fields, its toxicity is frequently ignored. It can be allergenic, carcinogenic or toxic to many organs such as pancreas, liver, kidney and brain.

Aim: To study the toxic effects of formalin on health of first year medical and dental students.

MaterialsandMethods: Thecross-sectionalstudy wasconducted over a period of one year (February 2019 to January 2020) in the Department of Anatomy, SMBT Institute of Medical Sciences and Research Center, Dhamangaon, Nashik, Maharashtra. This questionnaire based study was conducted on 200 first year medical and dental students. The percentage distribution of incidence of toxic effects of formalin pertaining to symptoms was calculated using Microsoft Excel 2019 spreadsheet software. The data were presented as frequency and percentage.

Results: Out of 200 students, 180 students (85 females and 95 males) completed and returned the questionnaire. The toxic effects of formalin with symptoms such as lacrimation in $63.33 \%$, itching of eyes in $81.67 \%$, running nose in $51.11 \%$, redness of eyes in $55 \%$, burning of eyes in $80.5 \%$, and headache in $42.22 \%$ of subjects were observed. The results were compared with previous studies conducted.

Conclusion: Formalin toxicity is of concern to people working closely with it including embalmers, anatomists, medical and dental students. Awareness will bring a positive effect on their health. Also, through research, we will be able to contribute towards prevention of occupational hazards, rehabilitation of affected persons and dissemination of knowledge.

Keywords: Disinfectant, Fixative, Occupational hazard, Preservative, Toxicity

\section{INTRODUCTION}

Formalin is a common fixative, preservative and disinfectant and is widely used for microscopy and histology [1]. Despite its extensive use in different fields, the toxicity of formalin is frequently ignored [2].

The World Health Organisation (WHO) has developed a guideline for formaldehyde concentration in non occupational settings to be at $100 \mathrm{ppb}$ for 30 minutes [1]. Although formalin is metabolised in body to formic acid which is a non toxic compound excreted in urine or converted to $\mathrm{CO}_{2}$ or excreted by lungs, it can be allergenic or carcinogenic, or toxic to many organs such as pancreas, liver, kidneys and brain [3].

Dissection of cadaver lays down a strong foundation for sound clinical knowledge and good clinical practice. During anatomy dissection, the fumes of formaldehyde from cadavers, embalming fluid, could negatively affect medical and dental students as well as anatomy teaching and non teaching staff.

Previous studies done by Nisa G et al., Jain SR et al., Alnagar FA et al., Kundu S and Gangrade P, Yadav A and Yadav M, Dixit D, Raja DS and Sultana B, Patil GV et al., Uddin MN et al., Ahmed $Y$ et al., Ramya $G$ et al., Jain $R$ et al., and Chaudhari $G$ et al., have studied the effects of formalin on medical students [1-13]. The present study was undertaken to confirm the findings of previous studies and also to observe the effects of formalin in the institute in order to help identify measures that can be taken to prevent them. Through this study, author wanted to disseminate knowledge and create awareness among students regarding precautions to be taken to minimise the effects of formalin. Therefore, this present study was conducted to observe toxic effects of formalin on first year medical and dental students in terms of incidence of symptoms.

\section{MATERIALS AND METHODS}

This cross-sectional study was conducted over a period of one year (February 2019 to January 2020) in the Department of Anatomy, SMBT Institute of Medical Sciences and Research Center, Dhamangaon, Nashik, Maharashtra. Ethical clearance from the Institutional Ethical Committee for carrying out the study (Approval letter No SMBT/IEC/19/640 dated 16/01/2019) was taken. A written informed consent was taken from all of them.

Inclusion criteria: First year MBBS and dental students of age 18 years and above without any co-morbidities were included.

Exclusion criteria: Students below 18 years of age and those who were not willing to participate, students having pre-existing respiratory, dermatological conditions or allergy were also excluded from the study.

Sample size calculation: Sample size was based on the number of students admitted to the courses. Total 200 subjects (150 first year MBBS students and 50 first year BDS students) were included.

\section{Procedure}

A questionnaire based study was conducted on 200 subjects (150 first year MBBS students and 50 first year BDS students) who were routinely exposed to formalin during dissection for at least two hours a day and three days a week. Composition of formalin solution used is 10 percent prepared by mixing one part of 37\% formaldehyde aqueous solution and nine parts water [14].

The students were given a questionnaire and were asked to fill it up. The self-administered questionnaire of this study included two parts. The first part included information about the demographic profile of the students (age, sex, medical course). The second part listed 21 effects of formalin on eyes, nose, mouth, respiratory tract, Gastro-intestinal Tract (GIT) and skin based on previous studies [1-8]. The cronbach's alpha value was 0.7. The students were 
asked to mention which of the effects listed in the questionnaire were experienced by them in the dissection hall during the year.

After completion of the study, an awareness session was conducted for all first year medical and dental students exposed to formalin. It included information regarding all preventive measures and also precautions to be taken while being exposed to formalin. The session included various parameters for betterment of health and was delivered via seminar-cum-skit and also audiovisual clip. It also included preventive measures to be taken by non teaching faculty (embalmers) while embalming and handling the concentrated formalin. In order to prevent the toxic effects of formalin on their health, all the subjects were taught the use of necessary protective equipments like goggles, aprons, gloves, mask, etc.

\section{STATISTICAL ANALYSIS}

The answer to the questionnaires were collected and the data were analysed using Microsoft Excel 2019 spreadsheet software. The incidence of the toxic effects was calculated and expressed as percentage. Severity of the effects was not studied.

\section{RESULTS}

Out of 200 students, 180 students (85 females and 95 males) completed and returned the questionnaire. The age of females was in the range 18 to 20 years (mean $18.42 \pm 0.61$ ) and that of males was in the range 18 to 21 years (mean 18.8 \pm 0.93 ). The [Table/ Fig-1] shows percentage distribution of incidence of toxic effects of formalin pertaining to symptoms observed.

\begin{tabular}{|l|c|c|}
\hline Symptoms & $\begin{array}{c}\text { Number of students } \\
\text { (Out of 180) }\end{array}$ & Percentage (\%) \\
\hline Itching of eyes & 147 & 81.67 \\
\hline Burning of eyes & 145 & 80.5 \\
\hline Irritating smell & 132 & 73.33 \\
\hline Lacrimation & 114 & 63.33 \\
\hline Redness of eyes & 99 & 55 \\
\hline Running nose & 92 & 51.11 \\
\hline Headache & 76 & 42.22 \\
\hline [Table/Fig-1]: Incidence of toxic effects of formalin.
\end{tabular}

In addition to above symptoms, some symptoms were observed such as nausea (12\%), itching of skin (2\%), syncope (4\%), congested nose $(11 \%)$, shrinkage of palm skin (5\%), sore throat (4\%), dizziness (4\%), disturbed nocturnal sleep (1\%), dryness $(3 \%)$, respiratory infections (2\%), gastrointestinal infections (1\%), unusual thirst (1\%) and unusual tiredness (3\%).

\section{DISCUSSION}

In the present study, lacrimation was found in $63.33 \%$, itching of eyes in $81.67 \%$, running nose in $51.11 \%$, redness of eyes in $55 \%$, burning of eyes in $80.5 \%$ and headache in $42.22 \%$ of subjects. Comparison of toxic effects of present study with various studies is given in [Table/Fig-2] [1-5, 8-13]. According to the study done by Jain SR et al., lacrimation was found in $87.2 \%$, irritation/ dryness of throat in $34.4 \%$, tingling sensation in nose in $30.8 \%$ and headache in $6.4 \%$ of subjects [2]. In the study done by Nisa $\mathrm{G}$ et al., lacrimation was found in $88.1 \%$, running nose in $30.7 \%$, redness of eyes $20 \%$, irritation of throat $11.2 \%$ and skin problems in $10.8 \%$ of subjects [1].

According to the study done by Alnagar FA et al., burning of eyes was found in $75 \%$, lacrimation was found in $73 \%$, headache was found in $62 \%$, redness of eyes was found in $58 \%$ and irritation of eyes was found in $42 \%$ of the subjects [3]. While in the present study, itching of the eyes was the most common symptom.

According to the study done by Kundu S and Gangrade P, itching of eyes was found in $47.84 \%$, lacrimation was found in $89.36 \%$, headache was found in $62.77 \%$, running nose was found in $52.12 \%$, redness of eyes was found in $58 \%$ and unpleasant smell was found in $94.68 \%$ of the subjects [4]. As per the study done by Yadav A and Yadav $\mathrm{M}$, itching of eyes was found in $67 \%$, lacrimation was found in $24.67 \%$, headache was found in $14.67 \%$, running nose was found in $20.67 \%$ and unpleasant smell was found in $30 \%$ of the subjects [5].

According to the study done by Dixit $D$ the three most disturbing symptoms were, unpleasant smell, itching of eyes and excessive lacrimation [6]. Raja DS and Sultana B, in their study state that the immediate effects of that agent are nausea, headache, and ocular irritation that causes tear overflow and a burning sensation in the throat while long term exposure to formaldehyde can cause contact dermatitis, congenital defects, and cancer [7].

In the study done by Patil GV et al., lacrimation was found in $82 \%$ and headache was found in $8 \%$ of the subjects [8]. While in the present study, lacrimation was found in $63.33 \%$ and headache was found in $42.22 \%$ of the students. In the study done by Uddin MN et al., the most frequently reported symptoms by medical students of three medical colleges were unfavourable scent $(84.8 \%, 86 \%$, $76 \%)$, running nose with prickling sensibility (61.6\%, 82\%, 65.33\%), neuralgia/migraine $(52 \%, 86 \%, 62.67 \%)$, inflammation of eyes (63.2\%, 84\%, 66.67\%), inconvenience in breathing $(72.8 \%, 86 \%$, $66.67 \%)$, qualm $(80 \%, 84 \%, 60 \%)$, lacrimation $(87.2 \%, 86 \%$, $49.33 \%)$, sore throat $(49.6 \%, 64 \%, 66.67 \%)$, scabies $(53.6 \%, 78 \%$, $62.67 \%)$, giddiness $(63.2 \%, 72 \%, 64 \%)$, and blister $(52 \%, 70 \%$, and $65.33 \%)$, respectively [9].

\begin{tabular}{|c|c|c|c|c|c|c|c|c|}
\hline \multirow[b]{2}{*}{ Study } & \multicolumn{8}{|c|}{ Symptoms (\%) } \\
\hline & Place of study & Burning of eyes & Lacrimation & Redness of eyes & Irritating smell & Running nose & Headache & Itching of eyes \\
\hline Jain SR et al., [2] & Pune & - & 87.2 & - & 30.8 & - & 6.4 & - \\
\hline Nisa G et al., [1] & Srinagar & - & 88.1 & 20 & - & 30.7 & - & - \\
\hline Alnagar FA et al., [3] & Libya & 75 & 73 & 58 & - & - & 62 & 42 \\
\hline Kundu S and Gangrade P [4] & Raigarh & - & 89.36 & 58 & 94.68 & 52.12 & 62.77 & 47.84 \\
\hline Yadav A and Yadav M [5] & Bunde-Ikhand- MP & - & 24.67 & - & 30 & 20.67 & 14.67 & 67 \\
\hline Patil GV et al., [8] & $\begin{array}{l}\text { Mangalore- } \\
\text { Karnataka }\end{array}$ & - & 82 & - & - & - & 8 & - \\
\hline \multirow{3}{*}{$\begin{array}{l}\text { Uddin MN et al., [9] } \\
\text { (Study done in three colleges) }\end{array}$} & AFMC, Dhaka & - & 87.2 & 63.2 & 84.8 & 61.6 & 52 & - \\
\hline & AMC, Cumilla & - & 86 & 84 & 86 & 82 & 86 & - \\
\hline & EMC, Cumilla & - & 49.33 & 66.67 & 76 & 65.33 & 62.67 & - \\
\hline Ahmed $Y$ et al., [10] & Egypt - & - & - & - & 79.6 & 51.5 & 44.9 & 63.6 \\
\hline Ramya G et al., [11] & Chennai & 82.4 & - & - & - & - & 23.9 & - \\
\hline Jain $R$ et al., [12] & Bhopal, & - & 79.28 & - & 76.42 & 62.14 & 51.42 & 68.57 \\
\hline Chaudhari G et al., [13] & Dahod- Gujrat & - & - & - & - & - & 16.7 & - \\
\hline Present Study & Nashik & 80.5 & 63.33 & 55 & 73.33 & 51.11 & 42.22 & 81.67 \\
\hline
\end{tabular}


The study by Ahmed $Y$ et al., involving 167 students from the first and the second year at the Department of Anatomy showed that approximately $79.6 \%$ of the students suffered from unpleasant smell, followed by eye irritation (63.6\%), nasal irritation (51.5\%), headache (44.9\%), breathing difficulties (39.5\%), visual disturbance (29.5\%), lack of concentration (26.9\%), cough (25.1\%), lethargy and fatigue (19.2\%), nausea (18\%), digestive disturbance (14.4\%), sore throat and dryness (12\%), sleep disturbance (4.8\%) and fainting (6\%) [10].

Ramya $\mathrm{G}$ et al., in their study, found complaints of nausea in $18.7 \%$, headache in $23.9 \%$, irritation of eyes in $82.4 \%$, respiratory problems in $20.4 \%$ of 171 medical and dental students [11]. In the study by Jain $\mathrm{R}$ et al., $79.28 \%$ students of the 140 medical students reported excessive lacrimation and $57.14 \%$ students felt that it was the most irritating and troublesome symptom [12]. A total of $76.42 \%$ of students experienced unpleasant smell and $63.57 \%$ students felt that it was the first symptom to develop. Other symptoms reported were running nose $(62.14 \%)$, itching sensation in eyes $(68.57 \%)$, cough $(18.57 \%)$, sore throat $(20.71 \%)$, difficulty in breathing (24.28\%) and headache (51.42\%).

The study conducted on 324 first year MBBS students by Chaudhari $\mathrm{G}$ et al., found headache in $16.7 \%$, nausea in $8.6 \%$, lack of concentration in $12.7 \%$, difficulty in breathing in $17.6 \%$ and vomiting in $3.7 \%$ of students [13].

Increased formaldehyde concentration in dissection and embalming rooms is due to the following reasons:

- Poor working practices leading to spillage of fluid during embalming.

- Poor condition of cadaver causing embalming fluid to leak out of cadaver.

- Using high concentration of formaldehyde in embalming fluid (depends on factors like extent, size of oedema and stage of decomposition of cadaver)

- Poor ventilation of dissection rooms.

The primary routes of human exposure to formaldehyde are inhalation, eye and dermal contact. It then causes inflammatory changes in the mucosa which leads to the various symptoms seen in the students exposed to formalin [1].

\section{Limitation(s)}

The present study was limited by it's small sample size. Also, the severity of the effects was not assessed in the study. Further studies can be undertaken to overcome these limitations.

\section{CONCLUSION(S)}

In the present study, various toxic effects of formalin such as lacrimation, itching of eyes, running nose, redness of eyes, burning of eyes, headache, nausea, itching of skin, syncope, congested nose, shrinkage of palm skin, sore throat, dizziness, disturbed nocturnal sleep, dryness, respiratory infections, gastrointestinal infections, unusual thirst and unusual tiredness in subjects were observed. Formalin toxicity is of concern to people working closely with it including embalmers, anatomists, medical and dental students. Awareness will bring a positive effect on health of subjects. Through dissemination of knowledge, we will be able to prevent occupational hazards and rehabilitate affected individuals. Such awareness sessions can be conducted at institutional level every year at the time of commencement of the first year course of medical and dental students in order to prevent its adverse effects on their health.

\section{REFERENCES}

[1] Nisa G, Shah BA, Shahdad S, Jan N, Samoon S, Ahmad S. Acute toxic effects of formalin on first year MBBS students during dissection in gross anatomy laboratory. J Dent Med Sci. 2016;15(8):56-59.

[2] Jain SR, Nahar PS, Baig MM. Study of formalin toxicity in Ist MBBS students: Int J Sci Res. 2012;1(3):233-35.

[3] Alnagar FA, Shmela ME, Alrtib AM, Benashour FM, Buker AO, Abdalmula AM. Health adverse effects of formaldehyde exposure to students and staff in gross anatomy. Int J Sci Res Manag. 2018;6(2):27-36.

[4] Kundu S, Gangrade P. Study of the toxic effects of formaldehyde vapours within the dissection hall on the first year Indian medical students. Int $J$ Anat Res. 2015;3(2):1179-90.

[5] Yadav A, Yadav M. A study of the effects of formalin on first year MBBS students. Schol J Appl Med Sci. 2014;2(5B):1588-90.

[6] Dixit D. Role of standardized embalming fluid in reducing the toxic effects of formalaldehyde. Indian J Forensic Med Toxicol. 2008;2(1):01-06.

[7] Raja DS, Sultana B. Potential health hazards for students exposed to formaldehyde in the gross anatomy laboratory. J Environ Health. 2012;74(6):36-40.

[8] Patil GV, Shishirkumar, Thejeshwari, Apoorva D, Sharif J, Sheshgiri C, et al. Physical reactions of formalin used as cadaver preservative on first year medical students. J Evid Based Med Healthc. 2014;1(5):279-83.

[9] Uddin MN, Miah I, Akter N. Research on comparative analysis toxic effect of formalin on MBBS students of several Medical College in Bangladesh. Eur Sci J. 2019;15(12):1857-788

[10] Ahmed Y, Abdelsabour-Khalaf M, Abdelrahim E, Ghallab A. Toxic effects of formalin on the medical students of South Valley University following repeated exposure at the anatomy laboratories. Int J Vet Sci. 2020;3(1):80-86.

[11] Ramya G, Gayatri Devi R, Jothi Priya A. Systemic effects of formalin on medical and dental students: A questionnaire study. Drug Invention Today. 2018;10(10):2020-22.

[12] Jain R, Jain A, Marskole S. Noxious effects of formalin treated cadavers on medical students during dissection. J Evol Med Dent Sci. 2017;6(63):4584.

[13] Chaudhari G, Sonawane M, Singel TC. Importance of the human cadaveric dissection for learning anatomy by the first year MBBS students- An observational study. Indian J Clin Anat Physiol. 2020;7(2):177-81.

[14] University of Surrey [Internet]. Formalin Fixative; Available from: https://www. surrey.ac.uk/sites/default/files/Formalin-Fixative.pdf.

PARTICULARS OF CONTRIBUTORS:

1. Student, Department of Anatomy, SMBT Institute of Medical Sciences and Research Center, Dhamangaon, Nashik, Maharashtra, India

2. Associate Professor, Department of Anatomy, SMBT Institute of Medical Sciences and Research Center, Dhamangaon, Nashik, Maharashtra, India.

3. Assistant Professor, Department of Anatomy, Seth G S Medical College, Parel, Mumbai, Maharashtra, India.

NAME, ADDRESS, E-MAIL ID OF THE CORRESPONDING AUTHOR:

Dr. Dhaval Patil,

Flat No. 3, Nandanvan Building, Plot No. 444, Sai Section,

Ambernath-421501, Maharashtra, India.

E-mail: drdhavalpatil@gmail.com
PLAGIARISM CHECKING METHODS: [Jain Het al.]

- Plagiarism X-checker: Feb 09, 2021

ETYMOLOGY: Author Origin

- Manual Googling: Jul 15, 2021

- iThenticate Software: Sep 23, 2021 (18\%)

\section{AUTHOR DECLARATION:}

- Financial or Other Competing Interests: None

- Was Ethics Committee Approval obtained for this study? Yes

- Was informed consent obtained from the subjects involved in the study? Yes

- For any images presented appropriate consent has been obtained from the subjects. Yes

Date of Submission: Feb 08, 2021

Date of Peer Review: Apr 08, 2021

Date of Acceptance: Jul 17, 2021

Date of Publishing: Jan 01, 2022 